\title{
Sea Level Fingerprints in a Region of Complex Earth Structure: The Case of WAIS $\mathscr{A}$
}

\author{
CARling C. Hay, ${ }^{\mathrm{a}, \mathrm{b}}$ Harriet C. P. LaU, ${ }^{\mathrm{b}}$ NATAlya Gomez, ${ }^{\mathrm{c}}$ JACQUeline Austermann, ${ }^{\mathrm{d}}$ Evelyn \\ Powell, ${ }^{\mathrm{b}}$ Jerry X. Mitrovica, ${ }^{\mathrm{b}}$ Konstantin LATYChev, ${ }^{\mathrm{e}}$ And Douglas A. Wiens ${ }^{\mathrm{f}}$ \\ ${ }^{a}$ Earth and Planetary Sciences, Rutgers University, Piscataway, New Jersey \\ ${ }^{\mathrm{b}}$ Earth and Planetary Sciences, Harvard University, Cambridge, Massachusetts \\ ${ }^{\mathrm{c}}$ Earth and Planetary Sciences, McGill University, Montreal, Quebec, Canada \\ ${ }^{\mathrm{d}}$ Bullard Laboratories, Department of Earth Sciences, University of Cambridge, Cambridge, United Kingdom \\ ${ }^{\mathrm{e}}$ Department of Physics, University of Toronto, Toronto, Ontario, Canada \\ ${ }^{\mathrm{f}}$ Earth and Planetary Sciences, Washington University in St. Louis, St. Louis, Missouri
}

(Manuscript received 16 May 2016, in final form 29 October 2016)

\begin{abstract}
Sea level fingerprints associated with rapid melting of the West Antarctic Ice Sheet (WAIS) have generally been computed under the assumption of a purely elastic response of the solid Earth. The authors investigate the impact of viscous effects on these fingerprints by computing gravitationally self-consistent sea level changes that adopt a 3D viscoelastic Earth model in the Antarctic region consistent with available geological and geophysical constraints. In West Antarctica, the model is characterized by a thin $(\sim 65 \mathrm{~km})$ elastic lithosphere and sublithospheric viscosities that span three orders of magnitude, reaching values as low as approximately $4 \times 10^{18} \mathrm{~Pa}$ s beneath WAIS. Calculations indicate that sea level predictions in the near field of WAIS will depart significantly from elastic fingerprints in as little as a few decades. For example, when viscous effects are included, the peak sea level fall predicted in the vicinity of WAIS during a melt event will increase by about $20 \%$ and about $50 \%$, relative to the elastic case, for events of duration 25 and $100 \mathrm{yr}$, respectively. The results have implications for studies of sea level change due to both ongoing mass loss from WAIS over the next century and future, large-scale collapse of WAIS on centennial-to-millennial time scales.
\end{abstract}

\section{Introduction}

The geographic pattern of sea level change following the melting of ice sheets and glaciers is a strong function of the location and time scale of the ice mass change (Farrell and Clark 1976). In the special case of relatively rapid mass loss (i.e., melt events spanning decadal to centennial time scales), these geometries have come to be known as sea level fingerprints. While this specific class of variability has been recognized since the late 1800s (Woodward 1888), the so-called fingerprinting of sea level change received renewed attention beginning at the turn of the current century, following efforts to use widely distributed sea level observations to infer meltwater sources in both the modern (e.g., Mitrovica et al.

Supplemental information related to this paper is available at the Journals Online website: http://dx.doi.org/10.1175/ JCLI-D-16-0388.s1.

Corresponding author e-mail: Carling C. Hay, carlinghay@fas. harvard.edu
2001; Plag and Jüttner 2001; Plag 2006) and ice age (Clark et al. 2002) world.

Modern predictions of sea level fingerprints date to the work of Clark and Lingle (1977), who applied the gravitationally self-consistent sea level theory of Farrell and Clark (1976) to predict sea level changes in response to future melting of the West Antarctic Ice Sheet (WAIS). These predictions assumed a nonrotating Earth and fixed shorelines; the same governing sea level theory was adopted in many subsequent studies (e.g., Clark and Primus 1987; Conrad and Hager 1997). The assumption of fixed shorelines neglects migration due to either onlap or offlap of water at shorelines experiencing local sea level variations or changes in the perimeter of grounded, marine-based ice sheets.

Mitrovica et al. (2001) and Tamisiea et al. (2001) included the feedback of rotational effects into their predictions of sea level fingerprints; that is, their sea level theory included a term for the response to a centrifugal driving potential associated with load-induced polar motion. Moreover, Mitrovica et al. (2009) and Gomez et al. (2010) adopted a generalized sea level theory to 
incorporate shoreline migration into the calculations. The Gomez et al. (2010) study was focused on WAIS collapse, and they highlighted the importance of incorporating shoreline migration in predictions of sea level fingerprints following the retreat (or advance) of grounded ice in marine settings. Finally, Mitrovica et al. (2011) summarized various technical issues associated with the calculation of sea level fingerprints, investigated the relative accuracy of published predictions, and demonstrated that $3 \mathrm{D}$ variability in mantle elastic structure would have negligible impact on these predictions.

Nearly all predictions of sea level fingerprints have, to date, assumed that the melting events are sufficiently rapid that the model for Earth's mantle adopted in the calculations may be treated as being purely elastic. The exceptions are Bamber et al. (2009) and Mitrovica et al. (2009), who explored the importance of viscous effects in multicentury simulations of melting from WAIS and concluded that these effects were relatively minor. Both studies adopted one-dimensional (1D) mantle viscosity profiles common in global ice age studies, characterized by values in the range from $5 \times 10^{21}$ to $10^{22} \mathrm{~Pa}$. These models do not capture the complexity of the mantle's viscoelastic structure beneath WAIS, including both the range and lateral variability of viscosity.

The WAIS sits atop a major continental rift system (Wörner 1999) that is thought to have experienced at least two phases of extension since the breakup of Gondwana (e.g., Cande et al. 2000). Seismic evidence indicates that the lithosphere in the region is relatively thin $(\sim 65 \mathrm{~km})$, in contrast with the stable East Antarctic craton, which has a thickness in excess of about $200 \mathrm{~km}$ (e.g., Morelli and Danesi 2004; Heeszel et al. 2013). In addition, anomalously slow seismic velocities characterize the sublithospheric mantle (to a depth of $200 \mathrm{~km}$ ) below West Antarctica (Ritzwoller et al. 2001; Morelli and Danesi 2004; Hansen et al. 2014; Lloyd et al. 2015; Heeszel et al. 2016). Geodynamic modeling of the geological record in the area (Faccenna et al. 2008; Austermann et al. 2015) and seismic imaging (Emry et al. 2015) both indicate that this seismically slow region of the mantle is characterized by an active, thermal upwelling. Taken together, these studies suggest significant, 3D variations in lithospheric thickness and uppermantle viscosity, with a particularly strong gradient as one moves across the shallow mantle beneath the western to the eastern sectors of the continent.

Recent models of ongoing glacial isostatic adjustment (GIA) across Antarctica in response to the last ice age have incorporated $3 \mathrm{D}$ variations in mantle structure (e.g., Kaufmann et al. 2005; A et al. 2013; van der Wal et al. 2015), with viscosities as low as $3 \times 10^{18} \mathrm{~Pa}$ s beneath West Antarctica (Kaufmann et al. 2005). In this study we explore, for the first time, the impact of this variable viscoelastic structure on predictions of sea level fingerprints of relatively rapid WAIS mass loss. We will consider two case studies: mass loss over time scales of decades, characterized by thinning of ice cover, and centuries, where major collapse of grounded ice in marine-based settings is predicted (e.g., DeConto and Pollard 2016; Joughin et al. 2014; Levermann et al. 2014). The Maxwell time for mantle material with viscosity about $10^{19} \mathrm{~Pa}$ s is of order several years, and thus viscous effects may play a significant role in sea level changes over both time scales. That is, published fingerprints of WAIS melt based on elastic Earth modeling may be subject to significant error, particularly in the near field of the ice loss. The goal of this paper is to provide updated predictions of these fingerprints of melting in this region of complex, 3D viscoelastic Earth structure.

\section{Modeling}

Our sea level projections are based on the gravitationally self-consistent sea level theory described by Gomez et al. (2010), which incorporates time-varying shoreline geometries and Earth rotation variations. The calculations are simplified relative to typical ice age sea level calculations because the initial topography is known at the outset. In applying the sea level theory, viscoelastic adjustments of the solid Earth in response to both surface mass (ice plus ocean) loading and perturbations in the centrifugal potential are computed using the finite-volume software described in Latychev et al. (2005). Load-induced polar motion is calculated following the theory of Mitrovica et al. (2005).

Recent updates to the finite-volume software allow regional grid refinement within a global model domain of lower resolution. In the calculations described below, the zone of grid refinement extends from the South Pole up to approximately $60^{\circ} \mathrm{S}$ (the outer boundary is not axisymmetric) and vertically down from the surface to $350-\mathrm{km}$ depth; the grid is characterized by an average spatial (horizontal and vertical) resolution of $6 \mathrm{~km}$ to the base of the Moho, $12 \mathrm{~km}$ to a depth of $220 \mathrm{~km}$, and $25 \mathrm{~km}$ to $350-\mathrm{km}$ depth. Outside this region, these numbers increase to 12,25 , and $50 \mathrm{~km}$, respectively, where the latter resolution extends to the base of the mantle.

The sea level calculations require two main inputs: a model for 3D viscoelastic mantle structure and the space-time history of ice cover. We describe each of the inputs, in turn, below.

\section{a. Viscoelastic Earth models}

All Earth models have elastic and density structure given by the 1D seismic Preliminary Reference Earth 
Model (PREM; Dziewonski and Anderson 1981) and assume a Maxwell viscoelastic mantle rheology that is compressible in the elastic limit. We will consider three different Earth models distinguished by their structure within the mantle. The first is a purely elastic model $\left(\mathrm{M}_{\mathrm{EL}}\right)$. In this case, the computed sea level change depends only on the net change in ice volume between the beginning and end of the calculation and not on the duration of the simulation. (In practice, the elastic sea level change is computed by melting all ice in a single, instantaneous time step.) As noted above, the vast majority of fingerprint calculations have been performed using purely elastic Earth models. The second Earth model $\left(\mathrm{M}_{\mathrm{VE1D}}\right)$ assumes a depth-varying viscosity profile comprised of an elastic (effectively infinite viscosity) lithosphere of $96-\mathrm{km}$ thickness and uniform upper- and lower-mantle viscosities of $5 \times 10^{20}$ and $5 \times 10^{21} \mathrm{Pas}$, respectively. The model falls within the class of $1 \mathrm{D}$ viscosity models favored in most GIA-based inferences of mantle viscosity (e.g., Lambeck et al. 1998; Mitrovica and Forte 2004).

Finally, a third Earth model $\left(\mathrm{M}_{\mathrm{VE} 3 \mathrm{D}}\right)$ incorporates 3D variability in both the elastic thickness of the lithosphere and mantle viscosity. For the former, we adopt the lithospheric thickness model by An et al. (2015a) for the Antarctic plate and that by Conrad and LithgowBertelloni (2006) for the remaining plates. Both models are scaled to produce a mean lithospheric thickness of $96 \mathrm{~km}$, which results in a mean thickness of $65 \mathrm{~km}$ across West Antarctica and $200 \mathrm{~km}$ across East Antarctica (Fig. 1a).

The Earth model $\mathrm{M}_{\mathrm{VE3}}$ is constrained to have a spherically averaged depth profile that matches the model $\mathrm{M}_{\mathrm{VE1D}}$. The 3D viscosity variation below the lithosphere is estimated from seismic velocity heterogeneity using the multistep method discussed by Austermann et al. (2013). Because of the different geographical coverage and differences in resolution, we used a combination of three different seismic S-wave velocity models: within West and central Antarctica we used the model by Heeszel et al. (2016), for East Antarctica and the tip of the Antarctic Peninsula we used the model by An et al. (2015b), and for the rest of the globe we adopted the model called S40RTS (Ritsema et al. 2011). Figure S1 of the supplemental material illustrates these different domain geometries. The first two of the seismic models extend to $350-\mathrm{km}$ depth, and S40RTS is adopted at greater depths across the entire mantle.

We derived a regional average seismic velocity model by moving sequentially through the three seismic models, beginning with the S40RTS model (Ritsema et al. 2011). In particular, the S40RTS model was adopted as the global model. The An et al. (2015b) model was then patched into this global model, and at each depth its velocities were shifted up or down so that the average value across the full Antarctic domain of the An et al. (2015b) model matched the average of the S40RTS model over the same Antarctic domain. The Heeszel et al. (2016) model was then patched into the An et al. (2015b) model so that at each depth the average across its smaller domain matched the average across the same domain of the An et al. (2015b) model. Variations in seismic wave speed are mapped into temperature perturbations following the depth-dependent scaling profiles described in Latychev et al. (2005). For the scaling of temperature anomalies to viscosity perturbations we used the scaling factors $0.037,0.023$, and 0.04 for the models by Heeszel et al. (2016), An et al. (2015b), and S40RTS, respectively [see Austermann et al. (2013) for the definition of this parameter]. The scaling factor varies in order to account for the amplitude differences between the S-wave models and thus to avoid significant viscosity discontinuities across the model domains. The resulting viscosity model is shown in Figs. 1b-f and results in viscosities as low as about $10^{18}$ Pa s below Marie Byrd Land (blue asterisk in Fig. 1a).

\section{b. Ice melt geometries}

We will consider two different WAIS melt geometries. The first $\left(\mathrm{WA}_{1}\right)$, which follows most previous fingerprint analyses, will remove a thin uniform layer of ice across WAIS. While this is not a realistic melt scenario, our goal is to focus on the geographic perturbation to the sea level fingerprint driven by Earth model variability in the absence of changes in this signal associated with ice melt geometry. We will consider three different cases distinguished on the basis of the melt duration: 25,50 , and $100 \mathrm{yr}$.

The second, more extensive melt geometry $\left(\mathrm{WA}_{2}\right)$ is taken from a coupled ice sheet-sea level simulation of future WAIS melting described in Gomez et al. (2015). Figure 2 shows snapshots of ice thickness at the start, middle, and end of the simulation (we do not include any melt of the East Antarctic Ice Sheet). The simulation had a duration of $1000 \mathrm{yr}$, but for our purposes we simply treat it as a realistic scenario for the geometry of WAIS collapse and treat the total duration of the collapse as a free parameter in the sea level fingerprint modeling. In particular, we additionally consider durations of 100 , 300 , and $500 \mathrm{yr}$.

All of our sea level predictions will be normalized by the total eustatic sea level change associated with the melt scenario and are therefore nondimensional. The eustatic sea level change is the rise in sea level computed for each melt scenario by assuming no deformation of the solid surface or self-gravitation of the surface mass 

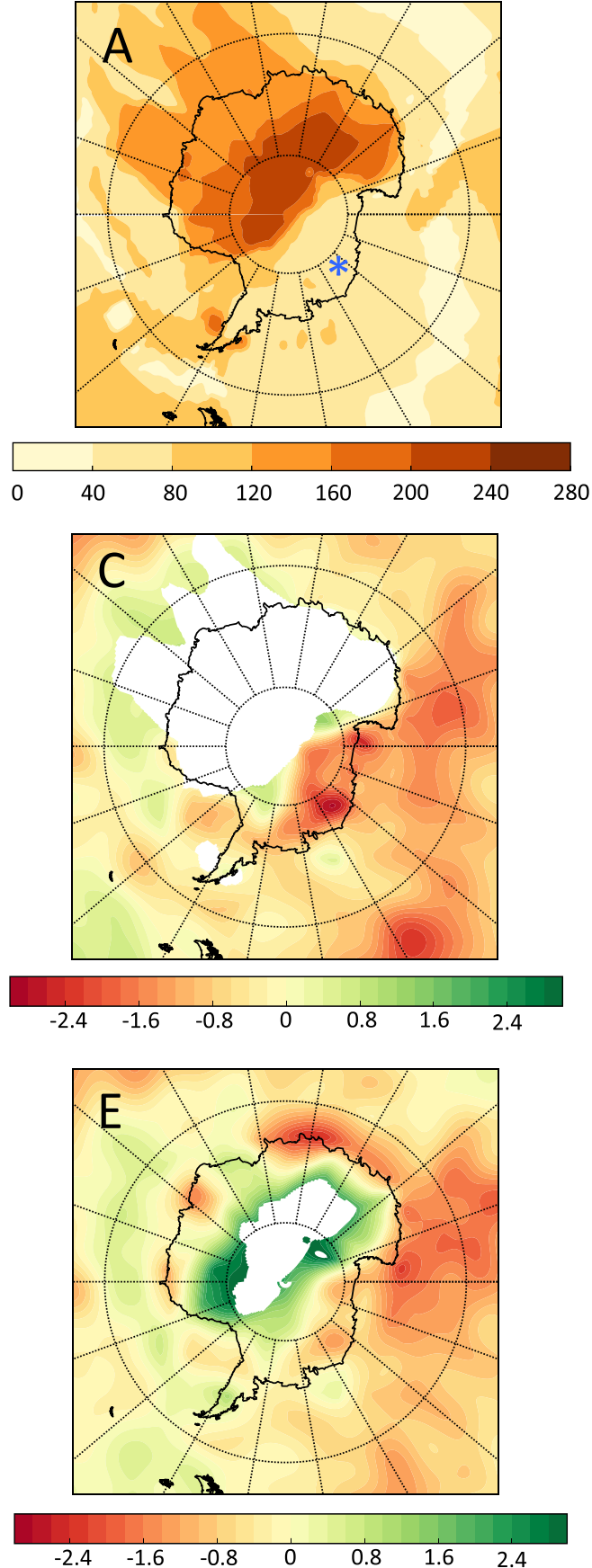
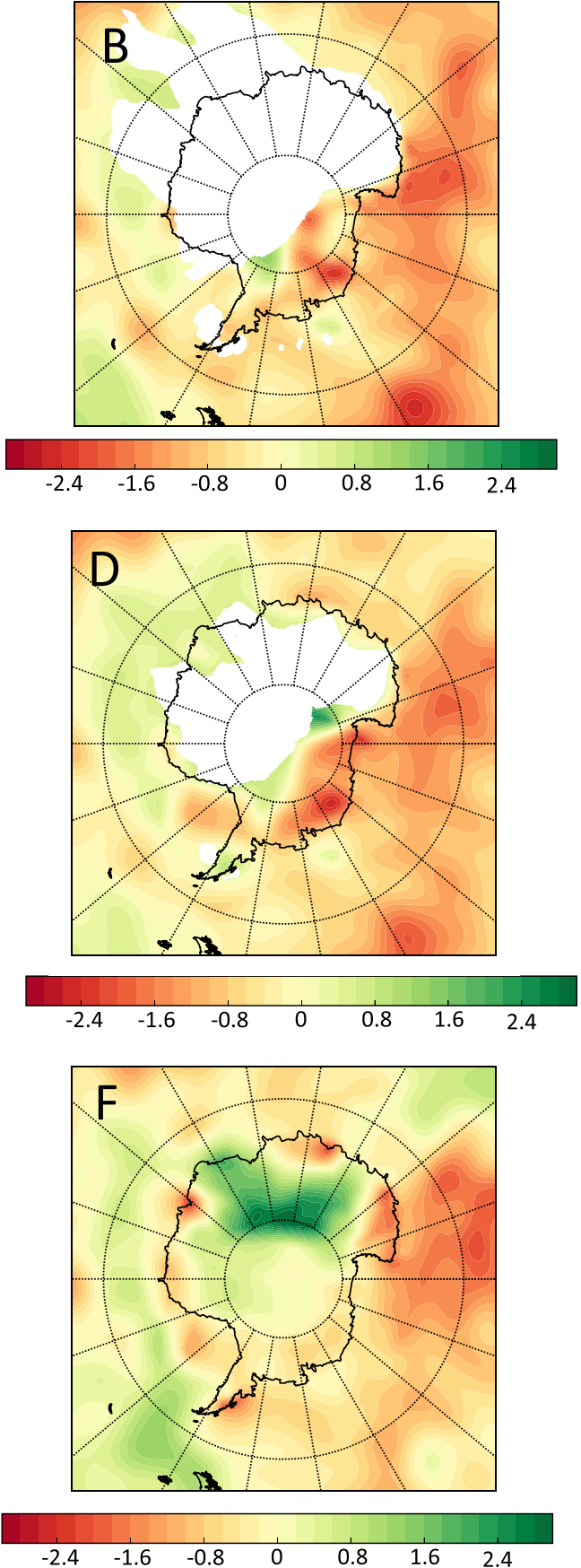

FIG. 1. Viscoelastic Earth model. (a) Lithospheric thickness (km) and mantle viscosity variations at depths of (b) 100 , (c) 125 , (d) 150 , (e) 200, and (f) $300 \mathrm{~km}$ in the $\mathrm{M}_{\mathrm{VE3D}}$ model described in the text. The logarithm of mantle viscosity variations relative to a background spherically averaged $\mathrm{M}_{\mathrm{VE1D}}$ model with lithospheric thickness of $96 \mathrm{~km}$, uppermantle viscosity of $5 \times 10^{20} \mathrm{~Pa}$ s, and lower-mantle viscosity of $5 \times 10^{21} \mathrm{Pas}\left[\log \left(\nu_{3 \mathrm{D}} / \nu_{1 \mathrm{D}}\right)\right]$ is represented in (b)-(f). White areas in (b)-(f) lie within the lithosphere. The blue asterisk in (a) indicates the location of Marie Byrd Land.

load. For the $\mathrm{WA}_{1}$ melt scenario, the eustatic sea level change is $1 \mathrm{~mm}$. In the case of scenario $\mathrm{WA}_{2}$, the effective eustatic sea level change (i.e., the uniform sea level change once all exposed marine-based sectors are filled with meltwater; Gomez et al. 2010) is $3.6 \mathrm{~m}$, consistent with estimates of maximum ice mass loss from WAIS (Bamber et al. 2009). As discussed by Mitrovica et al. (2011), normalized sea level fingerprints can be 

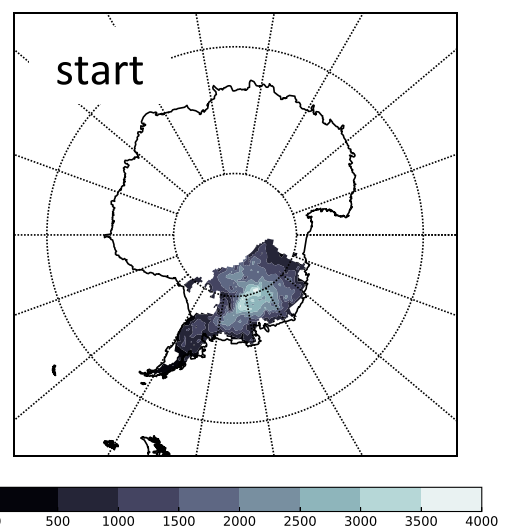
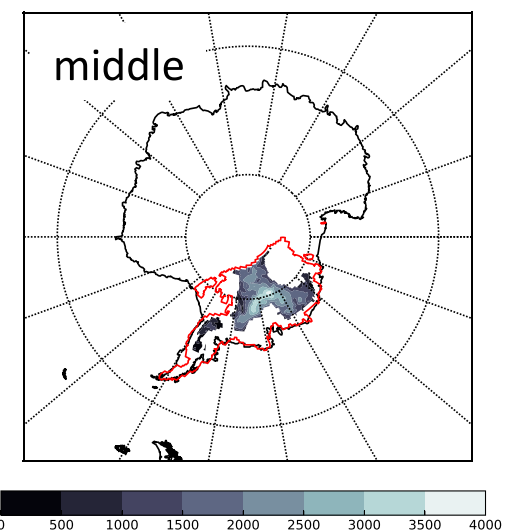
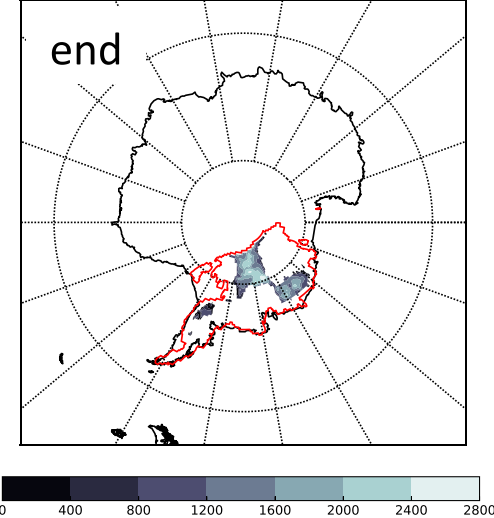

FIG. 2. Model of WAIS collapse. Snapshots of the thickness of the WAIS (m) at three times extending from the start, middle, and end of the $\mathrm{WA}_{2}$ ice history (see text). The red contour shows the extent of the ice sheet at the start of the simulation.

scaled to consider melt events of similar geometry but different net changes in ice mass.

\section{Results and discussion}

Our goal is to quantify the potential signal from viscous effects in sea level fingerprints of rapid WAIS melting, and therefore results obtained for viscoelastic Earth models $\mathrm{M}_{\mathrm{VE1D}}$ and $\mathrm{M}_{\mathrm{VE} 3 \mathrm{D}}$ will be shown relative to their associated (normalized) elastic fingerprint (Fig. 3). These elastic calculations show the features characteristic of previously published (elastic) sea level fingerprints of WAIS melting, including a zone of sea level fall in the vicinity of the ice melt that peaks about 9.4 and about 17.5 times the eustatic value for the $\mathrm{WA}_{1}$ and $\mathrm{WA}_{2}$ melt events, respectively, and a far-field sea level rise that peaks about $26 \%$ (for $\mathrm{WA}_{1}$ ) and $37 \%$ (for $\mathrm{WA}_{2}$ ) higher than the eustatic value in the North Atlantic, North Pacific, and Indian Oceans. The amplified signal in the near field is due to the more localized melt geometry. In the far field, the amplified signal for the $\mathrm{WA}_{2}$ simulation, relative to the $\mathrm{WA}_{1}$ case, is associated with an additional contribution in the former associated with meltwater being displaced by the uplift of exposed, marine-based sectors (Mitrovica et al. 2009; Gomez et al. 2010).

Figure 4 shows results in the Antarctic region for predictions based on the uniform ice melt geometry $\mathrm{WA}_{1}$ and three simulations distinguished on the basis of the duration of the melt event: 25,50 , or $100 \mathrm{yr}$. In all cases, we plot the total sea level change from the start to the end of the deglaciation. We note that if we continued the simulation beyond the end of the deglaciation, the impact of viscous effects on the sea level predictions would increase, and in this sense the results in Fig. 4 represent lower bounds on this impact.

We begin by considering viscoelastic calculations based on the 1D viscosity profile $\mathrm{M}_{\mathrm{VE1D}}$ (Fig. 4, left). As one would expect, the discrepancy from the elastic simulation (i.e., the signal from viscous effects) increases as the time scale of the melt event increases; specifically, the peak difference from the elastic case (Fig. 3a, inset) over West Antarctica is $1.1 \%, 2.1 \%$, and $4.5 \%$ for the 25-, 50-, and 100-yr simulations, respectively. As we have noted, the Earth model $\mathrm{M}_{\mathrm{VE1D}}$ is within the class of 1D Earth models commonly inferred in GIA analyses. We conclude that the predicted sea level fingerprint of WAIS melt based on such models will exhibit only minor differences from the associated elastic fingerprint for time scales of ice melt on the order of a century.

Next, we consider analogous results based on the more realistic viscoelastic Earth model MVE3D (Fig. 4, right). In contrast to predictions based on model $\mathrm{M}_{\mathrm{VE1D}}$, viscous effects become pronounced within just a few decades when $M_{V E 3 D}$ is adopted. In the near field, these viscous effects are characterized by localized sea level fall resulting from postglacial uplift in West Antarctica and an offshore zone of localized sea level rise resulting from the subsidence at the periphery, both of which are common features of ice age sea level predictions (e.g., Milne and Mitrovica 2008). The amplitude of these effects is nonnegligible; for the 25-, 50-, and 100-yr melt simulations, the peak sea level fall due to viscous effects occurs over the zone of minimum mantle viscosity (Marie Byrd Land; see Figs. 1b-f) and reaches amplitudes of $22.8 \%, 35.4 \%$, and $54.1 \%$ of the peak elastic signal. Thus, predictions of the near-field sea level fingerprint of WAIS melting spanning the next few decades to century should be based on modeling that incorporates the complex mantle viscosity structure below the region.

In Fig. 5, we turn to the simulations of WAIS collapse (model $\mathrm{WA}_{2}$ ) and consider collapse duration time scales of $100,300,500$, and $1000 \mathrm{yr}$. It is highly unlikely that a 

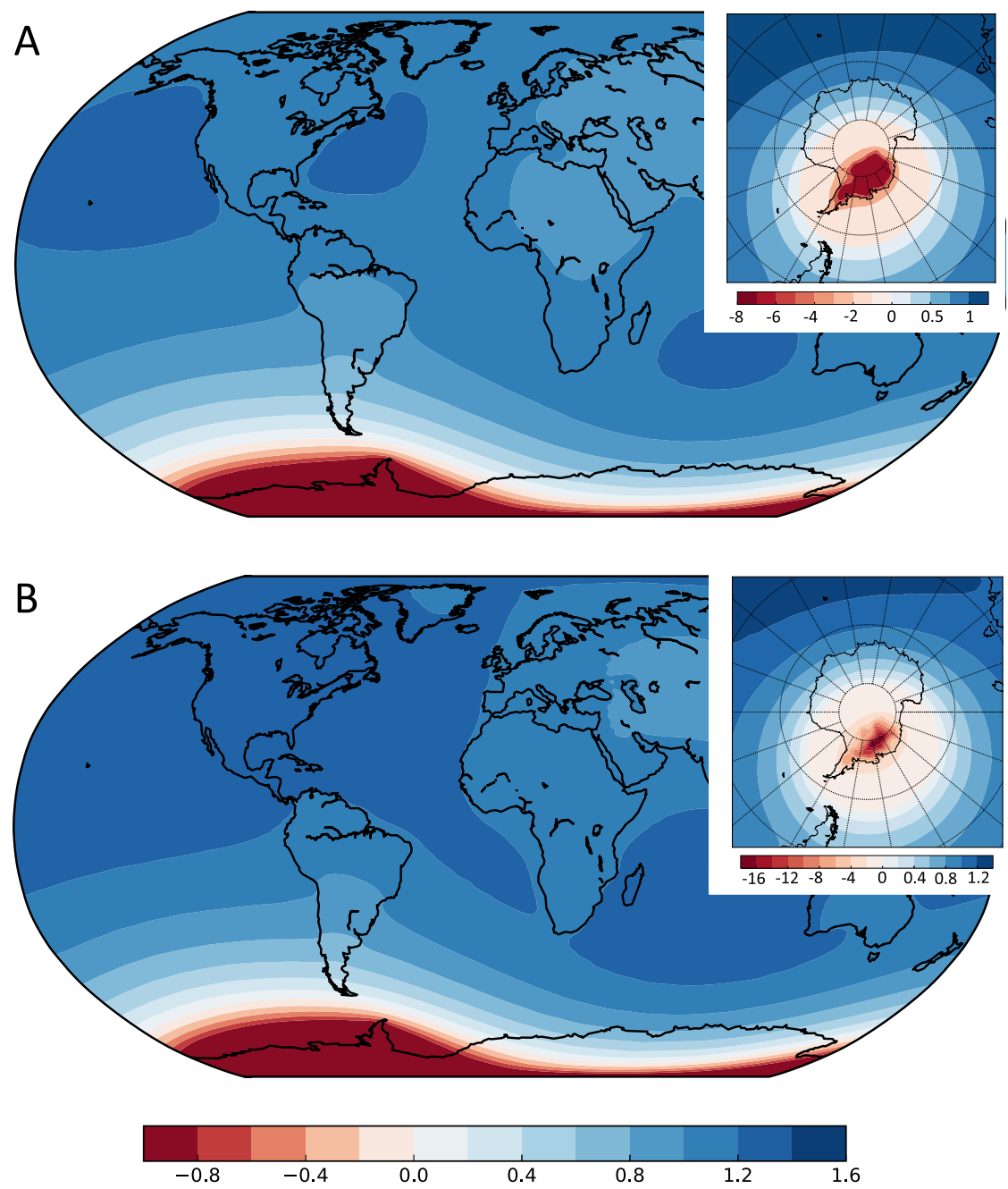

FIG. 3. Elastic sea level fingerprint of WAIS melt. (a) Normalized (dimensionless) sea level change across a simulation based on the $\mathrm{WA}_{1}$ ice history assuming a purely elastic Earth model. The peak sea level fall in West Antarctica is -9.37 and the peak far-field sea level rise is 1.26. (b) As in (a), but for the $\mathrm{WA}_{2}$ ice history (Fig. 2). In this case, the peak sea level fall in West Antarctica is -17.46 and the peak far-field sea level rise is 1.37. The predictions are normalized relative to the effective eustatic value of the adopted ice history. Since these calculations adopt an elastic Earth model, the predictions are independent of the modeled duration of WAIS collapse. Note that the color bar is saturated at -0.8 . The insets in both (a) and (b) show the normalized fingerprints centered over the South Pole.

collapse of the magnitude shown in Fig. 2 could occur in the next century (the maximum rate of eustatic sea level change is $\sim 50 \mathrm{~mm} \mathrm{yr}^{-1}$ in this case), but this case serves as a bridge to the time scales considered in the uniform melt case of Fig. 4. We again note the increased amplitude of localized zones of postglacial uplift (sea level fall) and peripheral subsidence (sea level rise) driven by viscous flow as the adopted duration of WAIS collapse increases. Moreover, as in the results of Fig. 4, predictions based on the $3 \mathrm{D}$ model $\mathrm{M}_{\mathrm{VE} 3 \mathrm{D}}$ significantly underestimate the impact of viscous effects on the WAIS fingerprint. In particular, while model $M_{V E 1 D}$ predicts a peak sea level fall over West Antarctica that is $5.6 \%, 16.5 \%, 26.9 \%$, and $50.5 \%$ greater than the elastic fingerprint for melt durations of $100,300,500$, and $1000 \mathrm{yr}$, respectively (Fig. 5, left), the analogous amplifications predicted using the 3D viscoelastic Earth model $\mathrm{M}_{\mathrm{VE3D}}$ are $53.1 \%, 110.5 \%, 152.3 \%$, and $222.2 \%$ (Fig. 5 , right).

To emphasize the importance of the viscous signal in the near field of WAIS, Fig. 6 shows the normalized 


\section{D viscoelastic - elastic 3D viscoelastic - elastic}
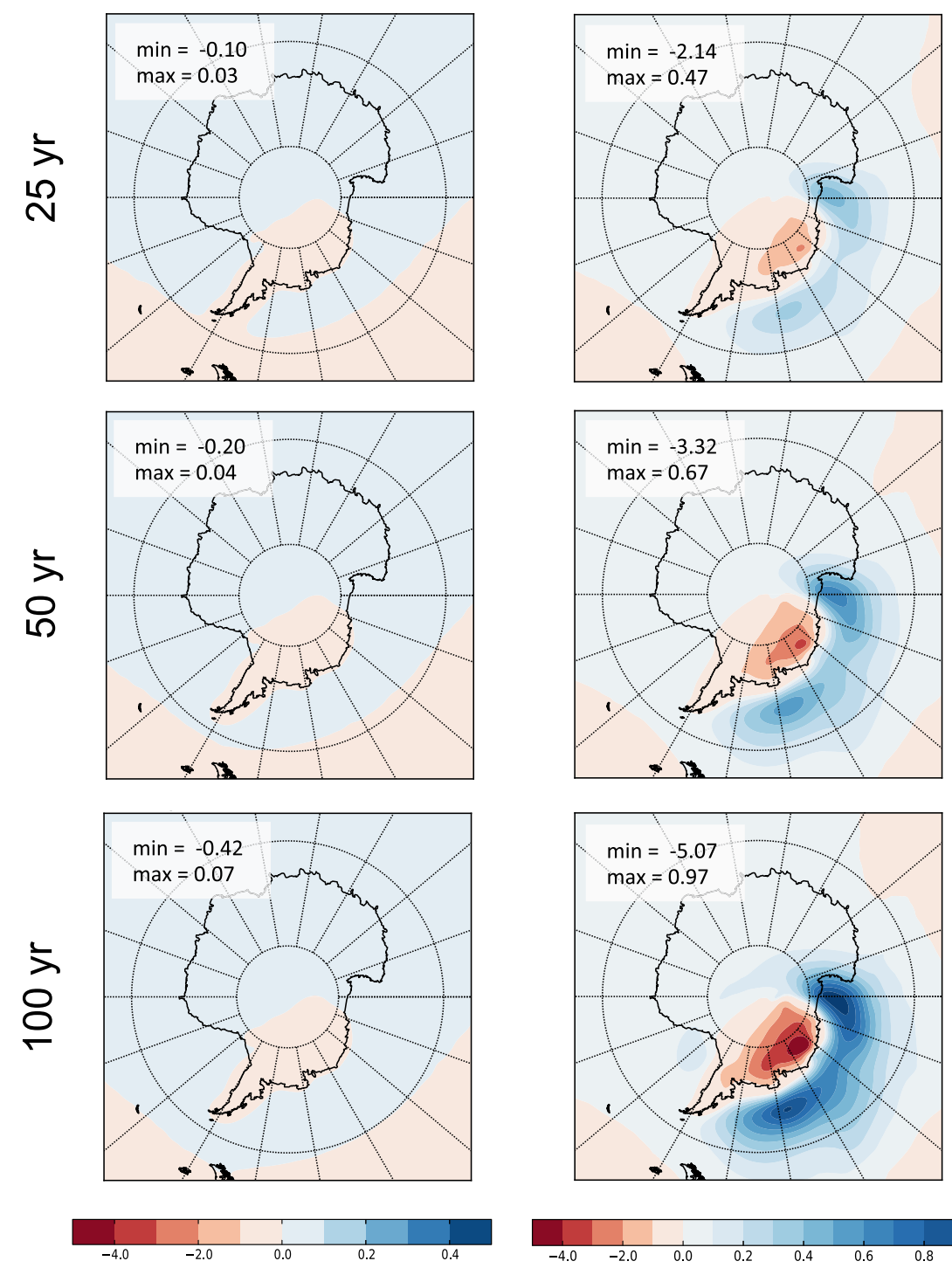

FIG. 4. Impact of viscous relaxation on computed sea level fingerprints for uniform WAIS melt. (left) Difference between the normalized sea level change for simulations based on the $\mathrm{M}_{\mathrm{VE} 1 \mathrm{D}}$ model and the $\mathrm{M}_{\mathrm{EL}}$ model (see text). Results are shown for WAIS melt events of duration (top) 25, (middle) 50, and (bottom) $100 \mathrm{yr}$. (right) As in (left), but the viscoelastic calculations are based on the $\mathrm{M}_{\mathrm{VE3D}}$ model (Fig. 1). All calculations are based on the $\mathrm{WA}_{1}$ (uniform thinning) ice history and are normalized by the effective eustatic value of this history (see text).

elastic fingerprint and the normalized total viscoelastic fingerprint computed using the realistic Earth model $\mathrm{M}_{\mathrm{VE3D}}$ for two cases: ice melt scenario $\mathrm{WA}_{1}$ and a melt duration of $50 \mathrm{yr}$ (Fig. 6a,b) and the collapse scenario $\mathrm{WA}_{2}$ and a melt duration of $500 \mathrm{yr}$ (Fig. $6 \mathrm{c}, \mathrm{d}$ ). In both cases, viscous effects clearly imprint a significant signature on the pattern and magnitude of the computed sea level fingerprints throughout the near field.
As a final numerical test, we considered the sensitivity of the results to variations in the magnitude of the lateral variability in mantle viscosity. As we noted above, the minimum viscosity below West Antarctica in the case of Earth model $\mathrm{M}_{\mathrm{VE3}}$ is approximately $10^{18} \mathrm{~Pa}$. We ran two additional simulations in which the scaling from seismic velocity to viscosity was varied to yield minimum viscosities of $2 \times 10^{17}$ and $5 \times 10^{18} \mathrm{Pas}$. These 


\section{$1 \mathrm{D}$ viscoelastic - elastic}
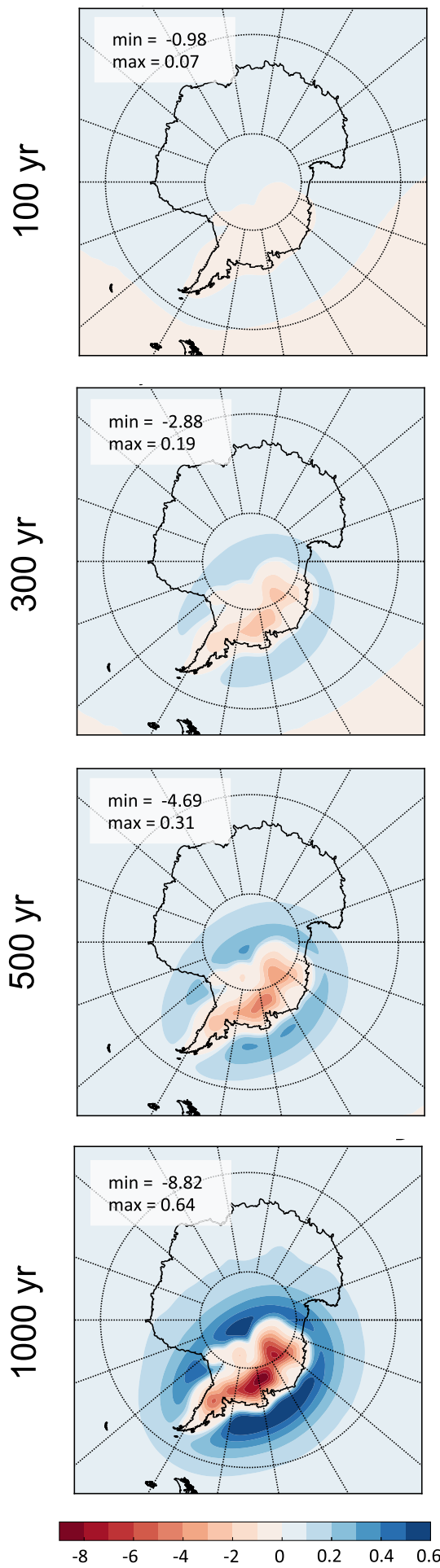

3D viscoelastic - elastic
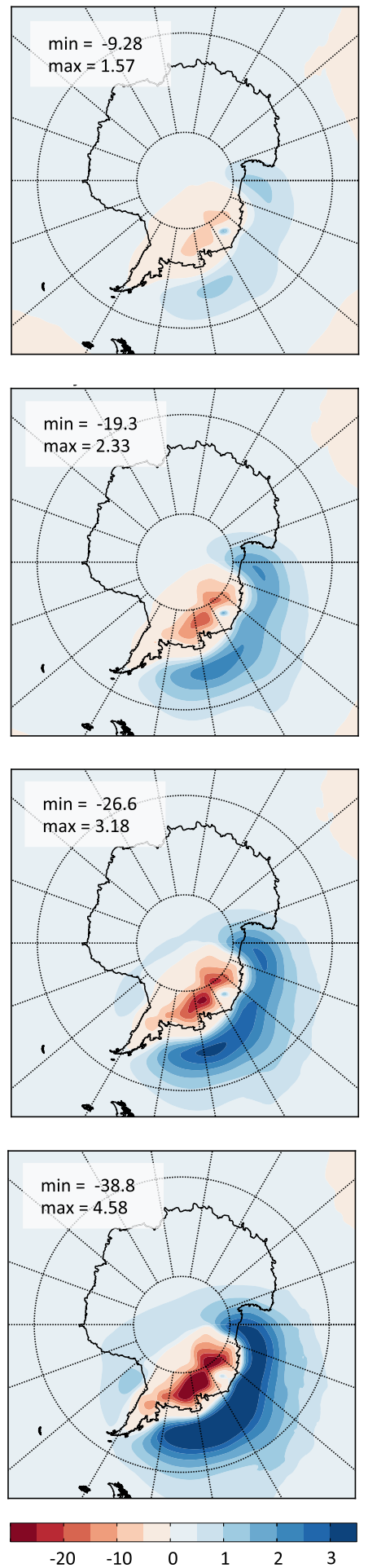

FIG. 5. Impact of viscous relaxation on computed sea level fingerprints of WAIS collapse. (left) Difference between the normalized sea level change based on the $\mathrm{M}_{\mathrm{VE1D}}$ model and the $\mathrm{M}_{\mathrm{EL}}$ model (see text). Results are shown for WAIS melt events of duration (top)-(bottom) $100,300,500$, and $1000 \mathrm{yr}$. (right) As in (left), but the viscoelastic calculations are based on the $\mathrm{M}_{\mathrm{VE3D}}$ model (Fig. 1). All calculations are based on the $\mathrm{WA}_{2}$ (WAIS collapse) ice history (Fig. 2) and are normalized by the effective eustatic value of this history ( $3.6 \mathrm{~m}$; see text). 
A

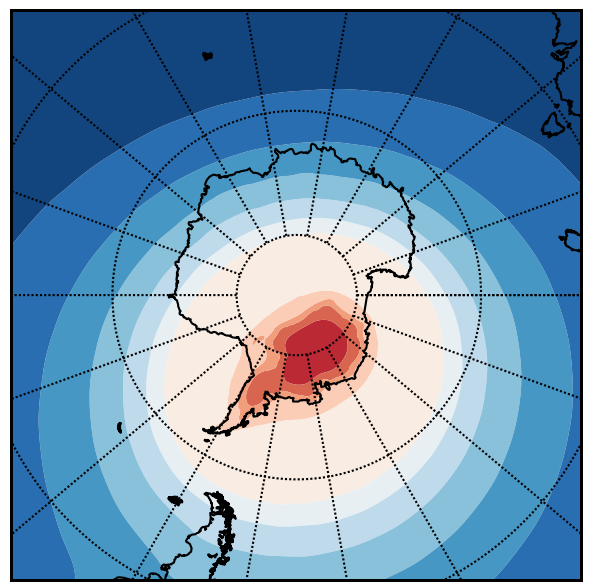

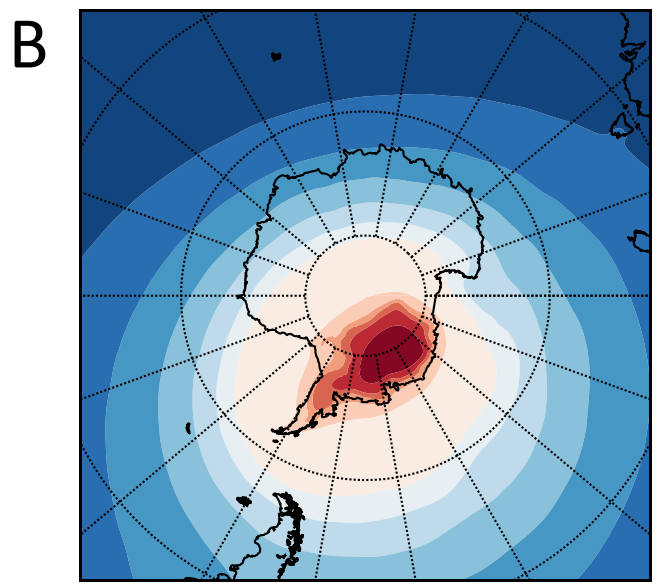

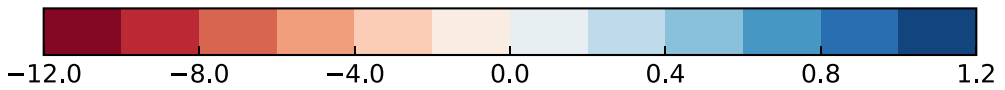

$-8.0$

C
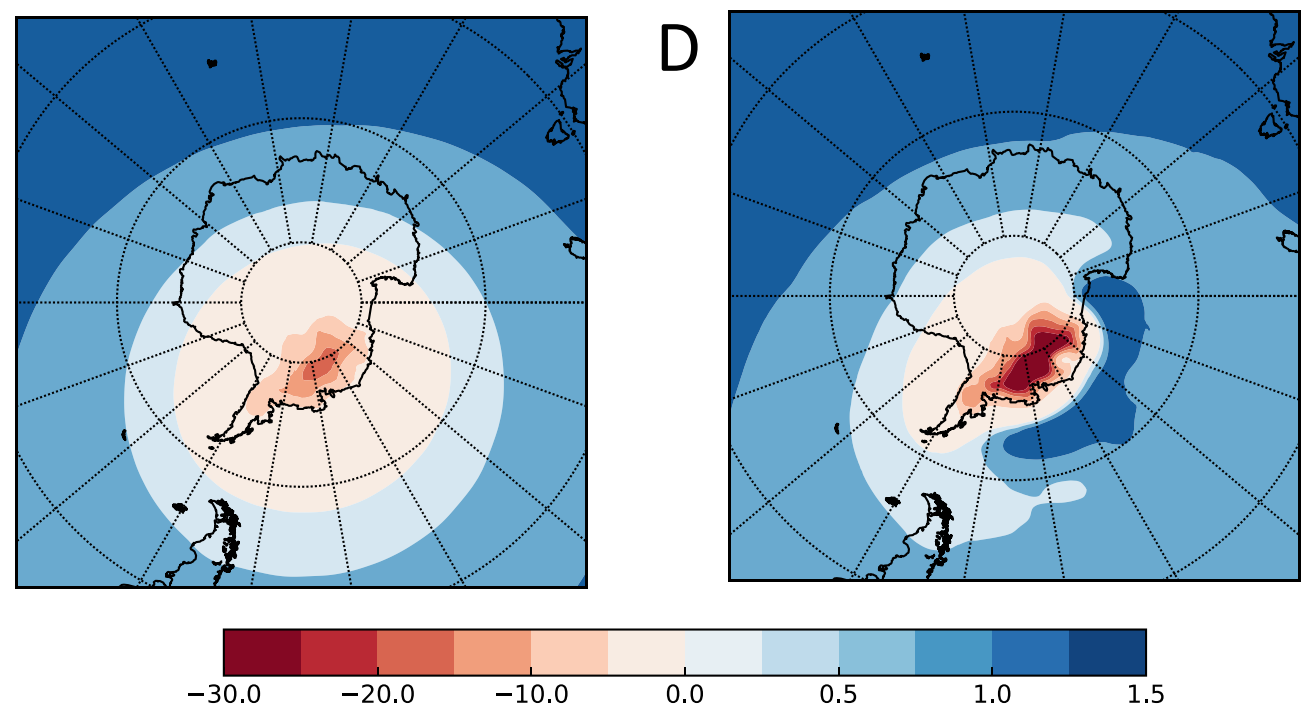

FIG. 6. The signature of viscous effects on the near-field sea level fingerprint of WAIS melt. (a) Normalized (dimensionless) sea level change across the $\mathrm{WA}_{1}$ ice history assuming a purely elastic Earth model. (b) Analogous fingerprint computed using the $\mathrm{M}_{\mathrm{VE3}}$ model and assuming a 50-yr melt duration. (c),(d) As in (a),(b), but for calculations based on the $\mathrm{WA}_{2}$ ice history. The computations for (d) assume a melt duration of $500 \mathrm{yr}$.

calculations were based on the WAIS collapse scenario $\mathrm{WA}_{2}$ and a melt duration of $500 \mathrm{yr}$. Figure 7 shows the total viscous signal (i.e., full calculation minus elastic results) for these simulations, together with the analogous result for model $\mathrm{M}_{\mathrm{VE} 3 \mathrm{D}}$ (reproduced from Fig. 5, bottom right). As one would expect, the viscous component of the sea level response increases with decreasing mantle viscosity; however, this signal remains significant even for the prediction based on the highest-viscosity Earth model. In particular, in order of decreasing viscosity, these simulations yield a maximum sea level fall that is $109.4 \%$,
$152.3 \%$, and $193.6 \%$ of the elastic response, respectively, at the end of the melting event.

\section{Conclusions}

Fingerprints of sea level change following the rapid melting of an ice sheet are almost exclusively computed by assuming that the solid Earth response to melting is purely elastic. This assumption is questionable in the case of ice mass changes in West Antarctica given that geological and geophysical evidence suggests that 

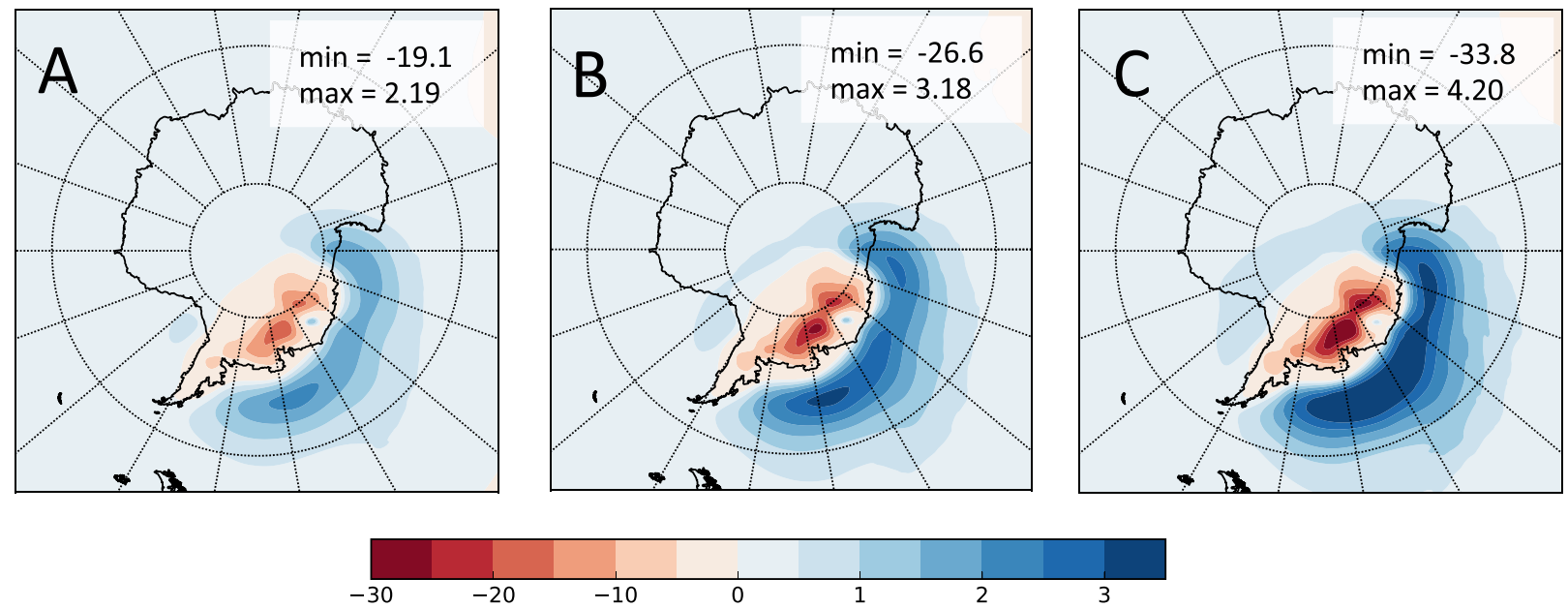

FIG. 7. Sensitivity of viscoelastic sea level predictions to the magnitude of lateral variations in mantle viscosity. Difference between the normalized sea level change based on the $\mathrm{M}_{\mathrm{VE3}}$ model and the $\mathrm{M}_{\mathrm{EL}}$ model. Results are shown for Earth models with a minimum viscosity of (a) $5 \times 10^{18}$, (b) $10^{18}$ (model $\mathrm{M}_{\mathrm{VE} 3 \mathrm{D}}$ ), and (c) $2 \times 10^{17} \mathrm{~Pa} \mathrm{~s}$, beneath West Antarctica. All calculations are based on the WA 2 (WAIS collapse) ice history (Fig. 2) with a melt duration of $500 \mathrm{yr}$, and they are normalized by the effective eustatic value of this history (3.6 m; see text).

sublithospheric viscosity below the region is approximately two orders of magnitude lower than values typically adopted in ice age sea level calculations. We have demonstrated, using a 3D viscoelastic Earth model consistent with available constraints, that sea level predictions in the near field of WAIS will depart significantly from previously published elastic fingerprints in as little as a few decades. This result has implications for studies of sea level change due to both ongoing mass loss from WAIS over the next century and large-scale collapse of WAIS on centennial-to-millennial time scales.

We have also demonstrated that the amplitude of these viscous effects is not accurately modeled using standard 1D viscosity profiles. As an example, both Bamber et al. (2009) and Mitrovica et al. (2009) considered the impact of viscous effects on the elastic fingerprints of WAIS collapse over time scales of centuries and longer by adopting 1D Earth models very similar to $M_{V E 1 D}$. We conclude that their calculations significantly underestimated the impact of viscous relaxation in the near field of the sea level fingerprints. More generally, our results also suggest that inferences of Antarctic ice volumes since the Last Glacial Maximum based, in part, on analyses of sea level datasets from the region and models akin to $\mathrm{M}_{\mathrm{VE1}}$ (e.g., Whitehouse et al. 2012) may need to be reevaluated.

Finally, the strong and geographically variable nearfield signal of viscous effects associated with the 3D model $\mathrm{M}_{\mathrm{VE3D}}$ (Fig. 6) suggests that coupled ice sheet-sea level models of WAIS evolution (e.g., Gomez et al. 2013, 2015) should, in future work, incorporate this complexity in viscoelastic Earth structure.
Acknowledgments. This work was supported by the U.S. National Science Foundation (Grants ARC-1203415, OCE-0825293, PLR-1142518, and PLR-1246712), the NJ Sea Grant Project 6410-0012, the Natural Sciences and Engineering Research Council of Canada Discovery Grant program, the Canada Research Chairs program, Harvard University, and McGill University.

\section{REFERENCES}

A, G., J. Wahr, and S. Zhong, 2013: Computations of the viscoelastic response of a 3-D compressible Earth to surface loading: An application to Glacial Isostatic Adjustment in Antarctica and Canada. Geophys. J. Int., 192, 557-572, doi:10.1093/gji/ggs030.

An, M., and Coauthors, 2015a: Temperature, lithosphereasthenosphere boundary, and heat flux beneath the Antarctic Plate inferred from seismic velocities. J. Geophys. Res. Solid Earth, 120, 8720-8742, doi:10.1002/2015JB011917.

- D. Wiens, Y. Zhao, M. Feng, A. A. Nyblade, M. Kanao, Y. Li, A. Maggi, and J.-J. Lévêque, 2015b: $S$-velocity model and inferred Moho topography beneath the Antarctic Plate from Rayleigh waves. J. Geophys. Res. Solid Earth, 120, 359-383, doi:10.1002/2014JB011332.

Austermann, J., J. X. Mitrovica, K. Latychev, and G. A. Milne, 2013: Barbados-based estimate of ice volume at Last Glacial Maximum affected by subducted plate. Nat. Geosci., 6, 553557, doi:10.1038/ngeo1859.

, D. Pollard, J. X. Mitrovica, R. Moucha, A. M. Forte, R. M. DeConto, D. B. Rowley, and M. E. Raymo, 2015: The impact of dynamic topography change on Antarctic ice sheet stability during the mid-Pliocene warm period. Geology, 43, 927-930, doi:10.1130/G36988.1.

Bamber, J. L., R. E. M. Riva, L. L. A. Vermeersen, and A. M. LeBrocq, 2009: Reassessment of the potential sea-level rise from a collapse of the West Antarctic Ice Sheet. Science, 324, 901-903, doi:10.1126/science.1169335. 
Cande, S. C., J. M. Stock, R. D. Muller, and T. Ishihara, 2000: Cenozoic motion between East and West Antarctica. Nature, 404, 145-150, doi:10.1038/35004501.

Clark, J. A., and C. S. Lingle, 1977: Future sea-level changes due to West Antarctic ice sheet fluctuations. Nature, 269, 206-209, doi:10.1038/269206a0.

— ture retreat of ice sheets: An effect of $\mathrm{CO}_{2}$ warming of the climate. Sea-Level Changes, M. J. Tooley and I. Shennan, Eds., Institute of British Geographers, 356-370.

Clark, P. U., J. X. Mitrovica, G. A. Milne, and M. E. Tamisiea, 2002: Sea-level fingerprinting as a direct test for the source of global meltwater pulse 1A. Science, 295, 2438-2441, doi:10.1126/ science.1068797.

Conrad, C. P., and B. H. Hager, 1997: Spatial variations in the rate of sea level rise caused by present-day melting of glaciers and ice sheets. Geophys. Res. Lett., 24, 1503-1506, doi:10.1029/ 97GL01338.

_ , and C. Lithgow-Bertelloni, 2006: Influence of continental roots and asthenosphere on plate-mantle coupling. Geophys. Res. Lett., 33, L05312, doi:10.1029/2005GL025621.

DeConto, R. M., and D. Pollard, 2016: Contribution of Antarctica to past and future sea-level rise. Nature, 531, 591-597, doi:10.1038/nature17145.

Dziewonski, A. M., and D. L. Anderson, 1981: Preliminary reference Earth model (PREM). Phys. Earth Planet. Inter., 25, 297 356, doi:10.1016/0031-9201(81)90046-7.

Emry, E. L., A. A. Nyblade, J. Julià, S. Anandakrishnan, R. C. Aster, D. A. Wiens, A. D. Huerta, and T. J. Wilson, 2015 The mantle transition zone beneath West Antarctica: Seismic evidence for hydration and thermal upwellings. Geochem. Geophys. Geosyst., 16, 40-58, doi:10.1002/ 2014GC005588.

Faccenna, C., F. Rossetti, T. W. Becker, and S. Danesi, 2008: Recent extension driven by mantle upwelling beneath the Admiralty Mountains (East Antarctica). Tectonics, 27, TC4015, doi:10.1029/2007TC002197.

Farrell, W. E., and J. A. Clark, 1976: On postglacial sea level. Geophys. J. Int., 46, 647-667, doi:10.1111/j.1365-246X.1976.tb01252.x.

Gomez, N., J. X. Mitrovica, M. E. Tamisiea, and P. U. Clark, 2010: A new projection of sea level change in response to collapse of marine sectors of the Antarctic Ice Sheet. Geophys. J. Int., 180, 623-634, doi:10.1111/j.1365-246X.2009.04419.x.

—, D. Pollard, and J. X. A. Mitrovica, 2013: 3-D coupled ice sheet-sea level model applied to Antarctica over the last 40 ky. Earth Planet. Sci. Lett., 384, 88-99, doi:10.1016/ j.epsl.2013.09.042.

-, , and D. Holland, 2015: Sea-level feedback lowers projections of future Antarctic ice-sheet mass loss. Nat. Commun., 6, 8798, doi:10.1038/ncomms9798.

Hansen, S. E., and Coauthors, 2014: Imaging the Antarctic mantle using adaptively parameterized P-wave tomography: Evidence for heterogeneous structure beneath West Antarctica. Earth Planet. Sci. Lett., 408, 66-78, doi:10.1016/ j.epsl.2014.09.043

Heeszel, D. S., D. A. Wiens, A. A. Nyblade, S. E. Hansen, M. Kanao, M. An, and Y. Zhao, 2013: Rayleigh wave constraints on the structure and tectonic history of the Gamburtsev Subglacial Mountains, East Antarctica. J. Geophys. Res. Solid Earth, 118, 2138-2153, doi:10.1002/ jgrb.50171.

_ and Coauthors, 2016: Upper mantle structure of the central and West Antarctica from array analysis of Rayleigh wave phase velocities. J. Geophys. Res. Solid Earth, 121, 1758-1775, doi:10.1002/2015JB012616.

Joughin, I., B. E. Smith, and B. Medley, 2014: Marine ice sheet collapse potentially under way for the Thwaites Glacier basin, West Antarctica. Science, 344, 735-738, doi:10.1126/ science.1249055.

Kaufmann, G., P. Wu, and E. R. Ivins, 2005: Lateral viscosity variations beneath Antarctica and their implications on regional rebound motions and seismotectonics. J. Geodyn., 39, 165-181, doi:10.1016/j.jog.2004.08.009.

Lambeck, K., C. Smither, and P. Johnston, 1998: Sea-level change, glacial rebound and mantle viscosity for northern Europe. Geophys. J. Int., 134, 102-144, doi:10.1046/ j.1365-246x.1998.00541.x.

Latychev, K., J. X. Mitrovica, J. Tromp, M. E. Tamisiea, D. Komatitsch, and C. C. Christara, 2005: Glacial isostatic adjustment on 3-D Earth models: A finite volume formulation. Geophys. J. Int., 161, 421-444, doi:10.1111/j.1365-246X.2005.02536.x.

Levermann, A., and Coauthors, 2014: Projecting Antarctic ice discharge using response functions from SeaRISE ice-sheet models. Earth Syst. Dyn., 5, 271-293, doi:10.5194/esd-5-271-2014.

Lloyd, A. J., and Coauthors, 2015: A seismic transect across West Antarctica: Evidence for mantle thermal anomalies beneath the Bentley Subglacial Trench and the Marie Byrd Land Dome. J. Geophys. Res. Solid Earth, 120, 8439-8460, doi:10.1002/2015JB012455.

Milne, G. A., and J. X. Mitrovica, 2008: Searching for eustasy in deglacial sea-level histories. Quat. Sci. Rev., 27, 2292-2302, doi:10.1016/j.quascirev.2008.08.018.

Mitrovica, J. X., and A. M. Forte, 2004: A new inference of mantle viscosity based upon joint inversion of convection and glacial isostatic adjustment data. Earth Planet. Sci. Lett., 225, 177189, doi:10.1016/j.epsl.2004.06.005.

—, M. E. Tamisiea, J. L. Davis, and G. A. Milne, 2001: Polar ice mass variations and the geometry of global sea level change. Nature, 409, 1026-1029, doi:10.1038/35059054.

— J. Wahr, I. Matsuyama, and A. Paulson, 2005: The rotational stability of an ice age Earth. Geophys. J. Int., 161, 491-506, doi:10.1111/j.1365-246X.2005.02609.x.

, N. Gomez, and P. U. Clark, 2009: The sea-level fingerprint of West Antarctic collapse. Science, 323, 753, doi:10.1126/ science. 1166510.

— - E. Morrow, C. Hay, K. Latychev, and M. E. Tamisiea, 2011: On the robustness of predictions of sea level fingerprints. Geophys. J. Int., 187, 729-742, doi:10.1111/j.1365-246X.2011.05090.x.

Morelli, A., and S. Danesi, 2004: Seismological imaging of the Antarctic continental lithosphere: A review. Global Planet. Change, 42, 155-165, doi:10.1016/j.gloplacha.2003.12.005.

Plag, H.-P., 2006: Recent relative sea-level trends: An attempt to quantify the forcing factors. Philos. Trans. Roy. Soc. London, 364A, 821-844, doi:10.1098/rsta.2006.1739.

and H. U. Jüttner, 2001: Inversion of global tide gauge data for present-day ice load changes. Proc. Second Int. Symp. on Environmental Research in the Arctic and Fifth Ny-Ålesund Scientific Seminar, Tokyo, Japan, National Institute of Polar Research, 301-318.

Ritsema, J., A. Deuss, H. van Heijst, and J. Woodhouse, 2011: S40RTS: A degree-40 shear-velocity model for the mantle from new Rayleigh wave dispersion, teleseismic traveltime and normal-mode splitting function measurements. Geophys. J. Int., 184, 1223-1236, doi:10.1111/j.1365-246X.2010.04884.x.

Ritzwoller, M. H., N. M. Shapiro, A. L. Levshin, and G. M. Leahy, 2001: Crustal and upper mantle structure beneath Antarctica 
and surrounding oceans. J. Geophys. Res., 106, 30 645-30 670, doi:10.1029/2001JB000179.

Tamisiea, M. E., J. X. Mitrovica, G. A. Milne, and J. L. Davis, 2001: Global geoid and sea level changes due to present-day ice mass fluctuations. J. Geophys. Res., 106, 30849-30863, doi:10.1029/2000JB000011.

van der Wal, W., P. L. Whitehouse, and E. J. O. Schrama, 2015: Effect of GIA models with 3D composite mantle viscosity on GRACE mass balance estimates for Antarctica. Earth Planet. Sci. Lett., 414, 134-143, doi:10.1016/j.epsl.2015.01.001.
Whitehouse, P. L., M. J. Bentley, G. A. Milne, M. A. King, and I. D. Thomas, 2012: A new glacial isostatic model for Antarctica: Calibrated and tested using observations of relative sea-level change and present-day uplifts. Geophys. J. Int., 190, 14641482, doi:10.1111/j.1365-246X.2012.05557.x.

Woodward, R. S., 1888: On the form and position of mean sea level. U.S. Geol. Surv. Bull., 48, 87-170.

Wörner, G., 1999: Lithospheric dynamics and mantle sources of alkaline magmatism of the Cenozoic West Antarctic Rift system. Global Planet. Change, 23, 61-77, doi:10.1016/S0921-8181(99)00051-X. 